\title{
Sisir Kumar Mitra, Scientific Achievements and the Fellowship of the Royal Society of London
}

\author{
Rajinder Singh*
}

(Received 01 October 2017)

\begin{abstract}
Sisir Kumar Mitra (1890-1963) was a Bengal based Professor of Physics at the University of Calcutta. He was the founder of ionospheric science and radio technology in India. He was one of the few physicists, whose names are connected with the Physics Nobel Prize and the Fellowship of Royal Society London. He was associated with various scientific institutions such as Indian National Science Academy, Indian Association for the Cultivation of Science and Asiatic Society of Bengal. In spite of high reputation and international achievements, little is written on him. The present communication gives: (i) a short review of S K Mitra's scientific work in the fields of optics, which he did under C V Raman, and (ii) S K Mitra's scientific achievements for which he was nominated and elected for the Fellowship of the Royal Society of London.
\end{abstract}

Key words: C V Raman, D-layer, FRS, Ionosphere, M N Saha, Nobel Prize, S K Mitra.

\section{INTRODUCTION}

S K Mitra had been one of the most successful Indian scientists. His contemporary M N Saha gave him credit in initiating ionospheric science (Saha, 1938, pp. 674-741), and as founder of ionosphere science ${ }^{1}$ and radio technology in history of science in India. His nomination to Physics Nobel Prize (Table 1) and election to Fellowship of the Royal Society of London (Table 2) also justifies these statements. However, only a few short papers are written on his life and work (Ratcliffe, 1994, pp. 501-502; Chattopadhyay, 2002, pp. 827-828; Mahanti, 2000, pp.92-99; Ramanathan, 1967, pp.268-281; Bose, 2010, pp. 510-17). My publication, Nobel Prize Nominator Sisir Kumar Mitra, FRS-His Scientific Works in International Context made through a German publisher (Singh, 2014) may also be consulted.

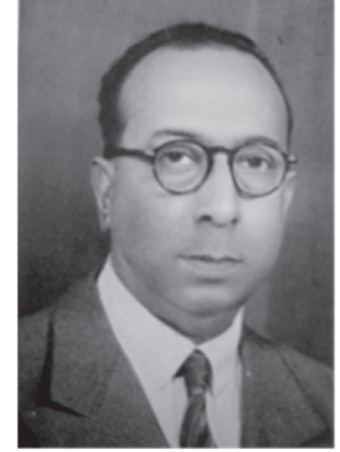

Fig. 1. S K Mitra, F R S (Courtesy: University of Calcutta) (Banerjee, et al 1957)

In the present communication I give a short review of:

a) Mitra's researches on light diffraction

b) It is scientific achievements for which he was nominated for the Fellowship of the Royal Society of London

\footnotetext{
* Research Group - Physics Education and History of Science, University of Oldenburg, Germany, Email: rajinder.singh@unioldenburg.de

1 For the history of the development of India's ionosphere research after 1960s, see, Mitra A P, Indian ionospheric research - S K Mitra to now, in Mitra A N (ed.), History of science, philosophy and culture in Indian civilization, Vol. XIII - Part I, India in the world of physics - Then and now, Pearson Longman, Delhi, 2009, pp. 517-540.
} 
Table 1. S K Mitra got most of the invitation among Indian physicists, for sending proposals for the Physics Nobel Prize in the time period of 1900-1965. ${ }^{4} \mathrm{C}$ V Raman belonging to a special category, because being a Nobel Laureate he had the permanent right of nomination

\begin{tabular}{|ll|}
\hline Nominator & Nominees (year for which the person was nominated for the Physics Nobel Prize) \\
\hline S K Mitra & M N Saha (1930, 1939, 1951, 1955) \\
D M Bose & M N Saha (1930) \\
& O Stern (1934), E Fermi and E O Lawrence (1938), E O Lawrence (1939), S Chandrasekhar \\
H J Bhabha & $(1957)$ \\
M N Saha & J D Cockcroft ${ }^{2}(1951) ;$ F Bloch (1952); W E Lamb Jr. (1953) \\
K Banerjee & A Sommerfeld (1951)3 \\
D S Kothari & S N Bose (1956) \\
G N Ramachandran & S N Bose (1959) \\
S N Bagchi & Norbert Wiener \& C.E. Shannon (1959) \\
Arun K Dutta & S N Bose (1962) \\
\hline
\end{tabular}

Table 2. Indian physicists elected to FRS till 1965 (Singh, 2016, p. 2016; Kocchar, 2001, pp. 721-722)

\begin{tabular}{|ll|}
\hline Year of Election & Name of Physicist \\
\hline 1920 & J C Bose \\
1924 & C V Raman \\
1927 & M N Saha \\
1940 & K S Krishnan \\
1941 & H J Bhabha \\
1944 & S Chandrasekhar \\
1958 & S K Mitra \& S N Bose \\
\hline
\end{tabular}

To start with Mitra's short biography is given, which is based on above referred to articles.

\section{Sisir Kumar Mitra - A short BIOGRAPHY}

Sisir Kumar Mitra was born on Oct. 24, 1890, at Konnagar, Calcutta. His father, Joy Krishna Mitra, was a school teacher. His mother,
Sarat Kumari, was a doctor at the Lady Dufferin Hospital, Bhagalpur. Mitra studied at the Bhagalpur District School and T N J College. At the time of his father's death, Mitra had yet not finished his F A (First Arts) examination. Later he joined the Presidency College Calcutta. In 1912, he did M.Sc. Physics from the University of Calcutta and won a Gold Medal. From 1913 to 1915 he was lecturer at the T N J College Bhagalpur; and the Christian College Bankura. In 1916, he was appointed as lecturer at the newly founded Science and Technology College, University of Calcutta. Mitra, who started under J C Bose as research scholar (Ghosh and Ghosh, 1995, pp.1150-1159); soon left to take Rashbehary Ghosh Research Scholarship, University of Calcutta. Mitra, Susilkumar Acharyya and Kumarnath Banerjee were the research scholars of the Department of Physics at the University of Calcutta (Gangopadhayay and Kundu, 2016, pp. 23-51).

\footnotetext{
2 H J Bhabha's this proposal was invalid as he sent it too late, that is, on Feb. 16, 1952.

3 There seems to be mistake on the webpage of the Nobel Foundation. Mrs. Maria Asp Dahlbäck - Archivist, Center for History of Science, Stockholm, on Dec. 22, 2015, wrote to me (Rajinder Singh) that "Saha in turn did not, as far as I can tell, submit a nomination."

4 The time period is limited until 1965 as according to the rules and regulations of the Nobel Foundation, documents older than 50 years can be consulted for research purposes.
} 
In 1920 he went to France for further studies. There he worked in the laboratories of Charles Fabry and Marie Skodowska-Curie; and obtained second D.Sc. degree. The abstract of his thesis: "Determination of spectroscopic standard wave-lengths in the short wave-length region" (Mitra, 1923, pp.315-339) was reported in the Journal of Chemical Society (Anonymous, 1923, ii595-ii596). It remains unclear, why Mitra left light scattering, in which he was quite successful; and turned his attention to wireless technology. The fact is, in France Mitra started research work with the French radio communication scientist Camille Gutton. In 1923, Mitra in the publication: "The demagnetization of iron by electromagnetic oscillations" (Mitra, 1923, pp. 1214-1217) concluded that "the demagnetization increases as the frequency of the oscillations is lowered" (Anonymous, 1923, p.727). This paper was read before the Paris Science Academy by G A Ferrié on April 30, 1923. His next article in co-operation with C. Gutton and V. Ylöstalö was "On the highfrequency discharge in rarefied gases" (Gutton, Mitra and Ylöstalö, 1923, pp.1871-1874). Before leaving for India, Mitra wrote a letter to Asutosh Mukherjee, Educator and Vice Chancellor of the University of Calcutta, and revealed his plan to initiate wireless technology at the University of Calcutta (Ghosh and Ghosh, 1995, pp.1150-1159).

After his return he was appointed as Khaira Professor of Physics. He initiated the teaching of wireless technology at the graduate level. In 1925, he established Wireless Laboratory and a radio transmitting station. From 1935 to 1955 he occupied the Ghosh Chair of Physics. In 1936, during a six month stay in UK, he visited different laboratories working on wireless technology; and sought support from the British scientific community for establishing Radio Research Board in India. He was one of the members of the Indian Scientific Mission, which visited UK and the U.S.A., in 1944-1945. In 1945 he published the monograph Active Nitrogen - A New Theory, Indian Press Ltd., Calcutta. His monumental book
The Upper Atmosphere, was published by the Asiatic Society of Bengal, Calcutta. From 1949 until his retirement in 1955, he was Professor at the Institute of Radio Physics and Electronics, University of Calcutta. From 1956 until 1962, he was an administrator of the Board of Secondary Education in West Bengal.

\subsection{Awards}

Gold Medal by the University of Calcutta (1912), King George V Silver Jubilee Medal (1935), Officer of the Most Excellent Order of the British Empire (1938), Joy Kissen Mookerjee Gold Medal - IACS (1943), Indian Science Congress Medal of the Asiatic Society of Bengal (1956), Fellowship of the Royal Society London (1958), Sir Deva Prasad Sarvadhikary Gold Medal - University of Calcutta (1961), Corresponding Member of the International Academy of Astronautics (1962), Presidential Award Padmabhushan, and National Research Professor (1962).

\subsection{Honours}

1934: Sectional President for Physics and Mathematics - Indian Science Congress Association (ISCA.); Secretary - Indian Association for the Cultivation of Sciences

1935: Foundation Fellow, National Institute of Sciences, India - Today known as Indian National Science Academy - INSA

1935, 1938: Local Secretary - ISCA; General Secretary (1939-1944)

1937: Member of the editorial team - "Indian Journal of Physics"

1943-1944: Vice President - INSA.

1943-1948: Chairman, Radio Research Committee

1948: Natural History Secretary (Physical Sciences), Asiatic Society of Bengal

1949-1950: Ordinary Member of the Council of the IACS. 
1951-1952: President, Asiatic Society of Bengal

1953-1954: Vice President - IACS.

1954: Member of Council - National Institute of Sciences, India

1955: President, ISCA.

1958: Elected FRS by the Royal Society of London

1959-1960: President INSA.

\section{WORK ON OPTICS UNDER CV RAMAN - A NEW THEORY OF HELIOMETER DIFFRACTION PATTERN BY Mitra}

Like Bidhu Bhushan Ray, S K Mitra started research career soon after Raman joined as Palit Professor in 1917. B B Ray's relation with C V Raman are explored in a separate article, in which it is shown that in the beginning of 1930s, Ray was one of the persons, who opposed Raman, when controversy broke due to Raman's control on the Indian Association for the Cultivation of Science (Singh, 2017, pp. 84-91). It is unknown, whether S K Mitra played any role; though he had reason to do so; because he was exploited by his teacher Raman, who wanted to have mechanics from J C Bose's workshop. For instance, on August 30, 1917, J C Bose complained to the Vice Chancellor of the Calcutta University:

"It has been reported to me that, on the
25 th. instant, a member of the Department
of Physics of the University College of
Science called at my Laboratory at the
Presidency College during my absence,
and with special instructions from Prof.
Raman to invite my senior mechanic to
transfer his services to the College of
Science Physical Department, with offer
of increased salary above what he gets
from me - even up to three times if
necessary. ... I must, therefore, formally
express to the University my regret that
from an institution, so important and so ambitious of making an honourable reputation as the College of Science, a transaction should be entered upon, of a kind do open to criticism even in commercial competition. It is not therefore merely from a natural feeling of resentment against so serious an attempt injury to my work and usefulness, that I bring this matter before you." 5

J C Bose forwarded the following statement to his mechanic:

"On Saturday the 25th, instant Babu
Shushil Kumar Acharya, accompanied by
his colleague Babu Shishir Kumar Mitra
saw me in Sir JC Bose's Laboratory in
the Presidency college during his absence
and informed me that he had been sent
by Prof. Raman to ask our senior
mechanic to see him (Prof. Raman) at an
early date with the view of his being
employed in the University College of
Science. I strongly resented this attempt
.... At this Babu Shushil Kumar Acharya
said that he was fully aware how
indispensable the mechanic was to Sir JC
Bose's important Researches and that he
had tried this best to dissuade Prof. Raman
from this course. ... Babu Shishir Kumar
Mitra said that Prof. Raman was
determined to have our mechanic at any
cost"6.

Mitra must had felt humiliated after he was drawn into such an issue; in particular, when he was exploited by Raman against his previous research guide J C Bose - A man highly respected in Bengal. Further research is needed to explore Mitra-Raman relation.

In 1917 while giving report about the progress of work in the Department of Physics, Raman appreciated Mitra's work as follows:

"Mr. Sisirkumar Mitra has shown most
praiseworthy activity during the current
year. One of the papers on the
'Asymmetry of the Illumination Curves
in Oblique Diffraction' is appearing in the

\footnotetext{
${ }^{5}$ Bose J C to Sarbadhikari D P, letter dated Aug. 30, 1917.

${ }^{6}$ Document written by J C Bose's assistant, dated Aug. 28, 1917.
} 
Philosophical Magazine, and a second paper on Sommerfeld's treatment of the Diffraction Problem is nearly ready for publication (Gangopadhayay and Kundu, 2016, pp. 23-51)."

Mitra enhanced Raman's previous work on diffraction of monochromatic light in an oblique single slit. Experimentally, Raman had found that the pattern on both sides of the central fringe was asymmetrical. Also, he gave an expression to calculate the intensity. Mitra proved the validity of Raman's formula for two or more parallel slits lying in the same plane (Mitra, 1920, pp.1-18). He continued this work in detail, which later led him to contrive a geometrical theory of the diffraction pattern observed in heliometer. However, before that, in 1910, P F Everitt, U K, applied the best available mathematical tools and numerically determined the exact nature of heliometer diffraction patterns. There was good agreement between his numerical and experimental results. Mitra found Everitt's work too much numerical and limited in scope. He gave a simpler method (Mitra, 1920, pp.1-18). In other
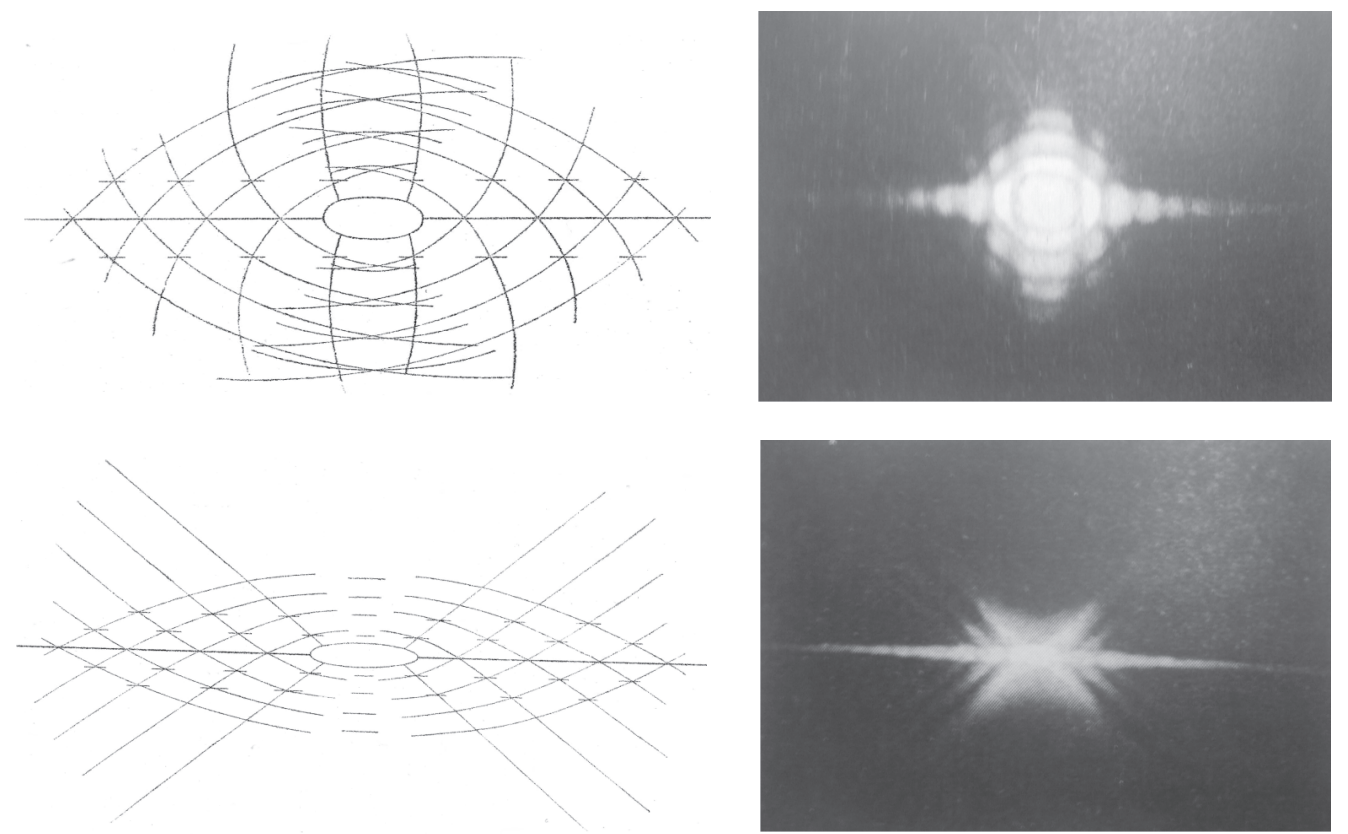

Fig. 2. Diffraction pattern based on Mitra's theory for circular aperture. Above: Circular aperture greater than a semi-circle; Below: Circular aperture smaller than a semi-circle (Courtesy University of Calcutta, Sir Asutosh Mookerjee Silver jubilee, Vol. II, 1922) 
and the thermionic oscillation generators were valuable appliances in wireless telegraphy (Fleming, 1919, p.1). For the thermionic current between a plane-heated cathode and a parallel anode, $\mathrm{H}$ Rakshit calculated the distribution of electron density; and showed that when current flows, the electron density diminishes immediately near to the hot surface (Rakshit, 1930, pp.80-87). The ionized atmosphere is an important factor in the propagation of radio waves. Mitra and Bhabani Charan Sil, Khaira Research Scholar in Physics, showed that while going from the lower to the higher frequencies the conductivity can decrease by more than 100 per cent (Mitra and Sil, 1932, pp.1081-1098).

\section{Study OF DifFerent IONOSPHERIC}

\section{LAYERS AND THE EXPERIMENTAL DISCOVERY OF THE D-LAYER}

Fig. 3 shows different layers of ionosphere with corresponding heights and electron densities. The path to gaining an understanding about this subject was very long. Seen in historical context, in 1902, Arthur Edwin Kennelly, USA, and nearly at the same time, Oliver Heaviside, UK, speculated an electrically conducting layer in the atmosphere that reflects the signals of the radio waves back to the earth. About two decades later, its experimental proof was given by E V Appleton and M A F Barnett (1925, pp.621-641). In 1927, Appelton, reported to have observed a new ionized layer. He named it the F-layer (Appleton, 1927, p.330).

Various publications show that "Mitra's School" was well-versed with the implementation of radio waves for the study of ionosphere (Mitra and Rakshit, 1929, pp.796-797). In the beginning of 1931, under the guidance of Mitra, H Rakshit started study of the E-layer under subtropical conditions (Rakshit, 1931, pp.897-907). In the following years "Mitra's school" studied the Eand F-layers under various conditions (Mitra et al, 1933, pp.442-443; Appleton, 1946, pp.691-691; Mitra, 1938, pp.914-915; Mitra, 1938, pp. 496497; Bhar and Syam, 1937, pp.513-528; Mitra and Kundu, 1954, pp.798-799).

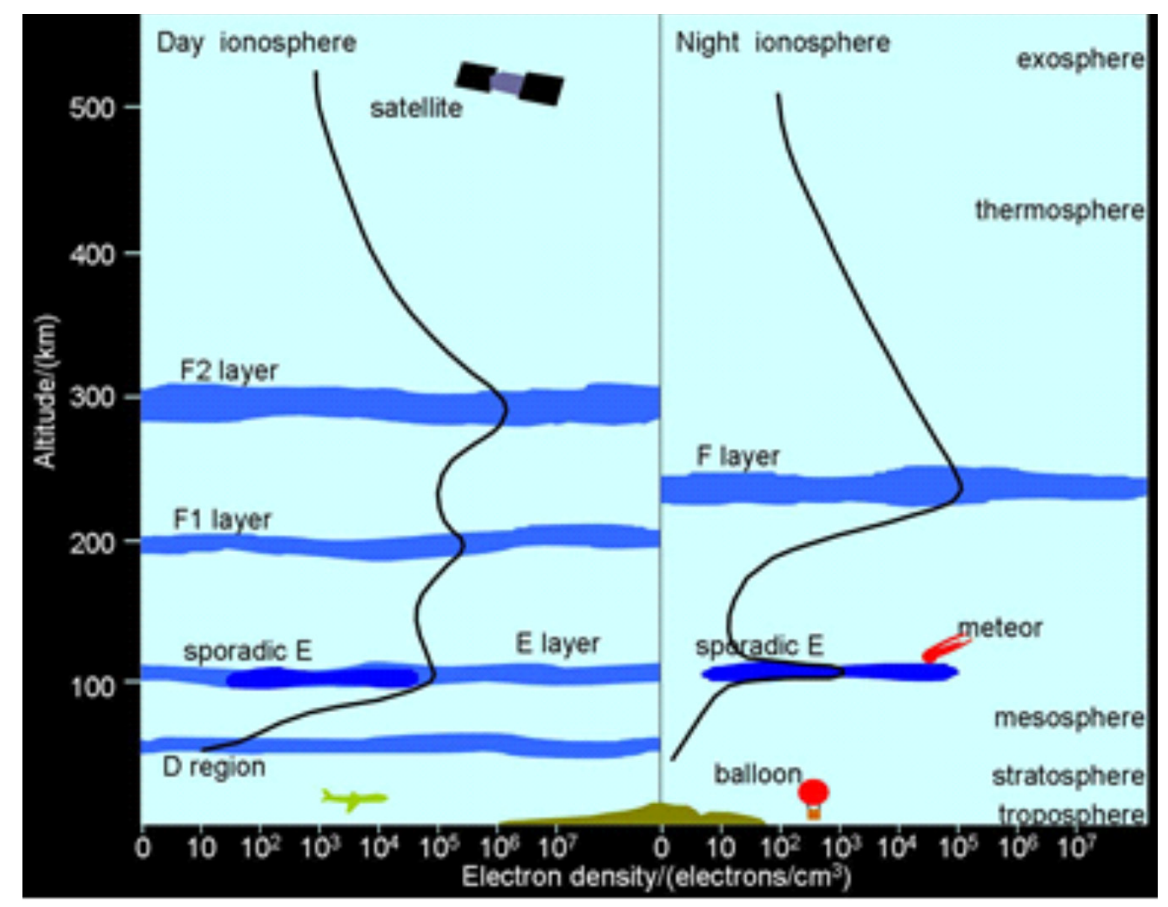

Fig. 3. Heights and electron densities of different ionospheric layers. (Courtesy, http://www.ips.gov.au/Educational/1/2/5, Jan. 10, 2014) 
In 1935, Mitra et al. reported that by using the pulse method, the echoes of radio waves returned from a height of ca. $55 \mathrm{~km}$ had been observed. Thus they experimentally discovered the D-layer (Mitra and Syam, 1935, pp.953-954). Further they showed that the $\mathrm{E}_{2}$ - and D-layers are caused by the photo-ionization of nitrogen and oxygen respectively. The $\mathrm{E}_{1}$-region is due to the second potential of $\mathrm{O}_{2}$ while the D-region is due to its first ionization potential (Mitra, Bhar and Ghosh, 1938, pp.455-465).

\section{The Master-piece Work - THE UPPER ATMOSPHERE}

According to "Preface" in the first edition of The Upper Atmosphere, in August 1935, the author, Mitra was invited by the National Institute of Sciences, India, to open a symposium on the ionosphere. His address "Present state of our knowledge of the ionosphere" was well appreciated by workers in different fields. About a year later, M N Saha suggested him to write a book on the atmosphere. Unfortunately, many publishers declined to publish the manuscript (Mitra, 2000, pp.3-4). Finally, due to Saha's efforts, the first version of the book came out in 1947. The book was dedicated to A V Appelton. In 1952, appeared the second edition (Fig. 4).

In 1953, a reviewer wrote: “..., the book is, and will remain, the standard work in its field. It is indispensable to those actually engaged on subjects coming within its scope, if only for the remarkably extensive bibliography, ...."7 In the beginning of the $21^{\text {st }}$ century, an author wrote: "Global change science began in India with the publication of the book The Upper Atmosphere by S K Mitra in 1947.",

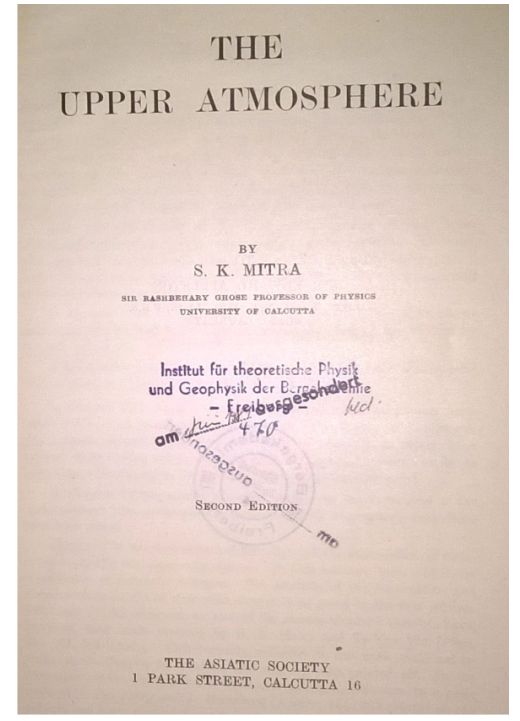

Fig. 4. Front page of Mitra's book. The German text "Institut für ...." shows that a copy of the book is at the library of the University of Freiburg, Germany". (Credit: Asiatic Society of Bengal, Calcutta)

\section{Foundation of the Radio Research BOARD}

On January 30, 1936, Mitra in a lecture at Maxwell Society at King's College London, stressed the cooperation between different countries and institutions for the study of atmosphere under different climate and geographical conditions (Mitra, 1936, 503-504). On May 5, 1936, in a meeting in London scientists from U K, Australia, and Canada stressed the importance of a Radio Research Board in India (Mitra, 1936, pp. 755-758 \& pp.430-432). On July 10, 1936, Mitra's lecture "Atmospherics" was broadcasted by the BBC. It was on the disturbances of radio signals due to technical defects and the atmosphere (Mitra, 1936, pp. 5035-4). In his talk, Mitra complained that about a decade ago he started radio researches in India;

\footnotetext{
B.H.B., The Upper Atmosphere. By S K Mitra. Calcutta (The Asiatic Society), 2nd Edition, 1952. Pp. xxiv, 713; 326 Figs., many tables. 48, Q. J. Roy. Meteor. Soc. 79(1953):571-572.

8 I.N.S.A., India and the global climate change, in: Pursuit and promotion of science - The Indian experience, Indian National Science Academy, New Delhi, 2001, pp. 144-152.
} 
but did not get support from Governmental institutions like the Meteorological and Postal Departments. About three years later, Mitra called the policy of the Government of support broadcasting, half-hearted (Mitra, 1940, pp.249$250)$. Due to his efforts, in 1942, the Radio Research Committee was established. In 1945 the Committee submitted a plan for the establishment of an Institute. In 1949, the Wireless Laboratory was converted into the Institute of Radio Physics and Electronics. Mitra became its Head and maintained the position until his retirement in 1955.

\section{After glow, Night SKy Luminescence ANd "The Ionic Theory of ACtive Nitrogen"}

In 1857, German Heinrich Geissler invented gas discharge tube. Later, some scientists observed that, after the charge was cut-off, a visibly whitish, shimmering cloud remained. This phenomenon came to be known as afterglow. By various authors the effect was attributed to either nitrogen or oxygen or oxygen and nitrogen, or water vapours (Morrem, 1862, pp.350-352, 1865, pp.643-654; Sarasin, 1870, pp.425-434; Hertz, 1883, pp.782-816; Trowbridge, 1924, pp.24-41; Anonymous, 1883, 403-405; Lewis, 1900, pp.815). R J Strutt, UK, stated that the effect is due to a "new form" of nitrogen, that is, an "active" modification of the pure element (Strutt, 1911, pp.219-229). In spite of much experimental as well as theoretical work by various scientists, there was still no satisfactory theoretical explanation. ${ }^{9}$ The problem was solved by S K Mitra with his "The Ionic Theory of Active Nitrogen" (detail below).

During the WWII Mitra's student, S N Ghosh made observations of night airglow emissions and diurnal intensity variations; whereas S S Baral measured the electron densities of the F-region. They noticed that the two variations follow a trend. This supported the hypothesis that night glow emission could also be a product of ionization of atmospheric constituents and subsequent recombination (Ghosh and Ghosh, 1995, pp.1150-1159). In 1943, Mitra found that night sky light has lines and bands, which are either green or red. He proposed that the F-layer of the ionosphere contains not only neutral nitrogen gas $\left(\mathrm{N}_{2}\right)$ and atomic-oxygen $(\mathrm{O})$, but also their ions $\left(\mathrm{N}_{2}^{+}, \mathrm{O}^{+}, \mathrm{O}^{-}\right)$and free electrons (Mitra, 1943, pp.46-48). He proposed the "ionic theory", according to which the collisions take place between nitrogen ion $\left(\mathrm{N}_{2}^{+}\right)$, electron $(e)$ and nitrogen gas molecules $\left(\mathrm{N}_{2}\right)$. During the process, nitrogen ions act as a major catalyst. When nitrogen molecules fall from one energy state to other state, radiation is emitted, which is observed as afterglow (Mitra, 1945, p. 61). The fundamental idea of the theory was initially given in different papers and lectures (Mitra, 1943, pp.46-48; 1943, pp.49-50; 1944, pp.133-134; 1944, pp.212-213; 1944 , pp.576-577; 1944, p.831). The details of the subject were published in a short monograph (Fig. 5) (Mitra, 1945, pp. 68-70).

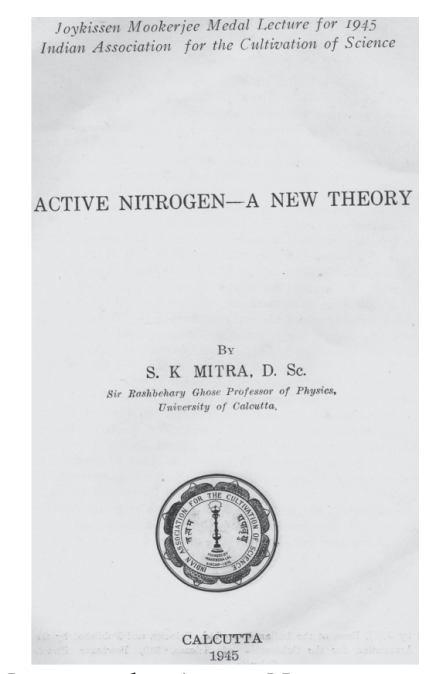

Fig. 5. The Monograph: Active Nitrogen - A New Theory. Facsimile of the title page of Mitra's monograph (Courtesy IACS, Kolkata)

\footnotetext{
9 Kneser H O, Über die Natur des aktiven Stickstoffs, Ann. Phys. 392(1928):717-736; Kenty C., Turner L.A., Surface layers on tungsten and the activation of nitrogen by electron impact, Phys. Rev. 32(1928):799-811; Rayleigh L., Further studies on active nitrogen - IV - The ionisation associated with active nitrogen, Proc. R. Soc. Lond. 180(1942):140-150.
} 
In Nature, AG Gayon, UK, while writing a review on Mitra's, book doubted, whether Mitra's theory can explain all facts (Gaydon, 1946, 751). In 1948, L Herman and R Herman, declared that Mitra's hypothesis is unable to explain all of the features of active nitrogen. They were of the opinion that strong emission in particular case is due to the recombination of the doubly ionized nitrogen ions $\left(\mathrm{N}_{2}^{++}\right)$and electrons (Harman and Harman, 1948, pp.1018-1019). The ultimate experiment to disapprove Mitra's "ionic theory" was performed by JM Benson, USA. He stated:

\begin{abstract}
"Microwave measurements of the free electron density in a stream of active nitrogen indicated one free electron for each $2.3 \times 10^{8}$ molecules in a stream. Contrary to Mitra's theory, probes in the stream were found to respond to carriers of negative ions rather than positive ions. Space discharges in an expanding stream of active nitrogen are attributed to free electrons moving with the stream (Benson, 1952, pp.757-764)."
\end{abstract}

Mitra realized the need for improvement of his dated theory and formulated "Metastable Atomic Theory of Active Nitrogen". According to it: "nitrogen ions and electrons were parent bodies of active nitrogen. By dissociation $\left(\mathrm{N}_{2}^{+}+e\right.$ $\rightarrow \mathrm{N}$ (excited) $+\mathrm{N}$ (excited)), the active nitrogen atoms in the ground states $\left({ }^{4} \mathrm{~S}\right)$, and a small part in the metastable states $\left({ }^{2} \mathrm{D}\right.$ and $\left.{ }^{2} \mathrm{P}\right)$ are produced (Fig. 6) (Mitra, 1953, pp.516-521)." With these suppositions he explained the Lewis-Rayleigh afterglow spectrum, presence of ionization in the glow, the negative temperature coefficient, and the dark modification (Mitra, 1953, pp.516-521).

In 1967, A N Wright stated Mitra's book as a comprehensive review on experimental development prior to 1945 (Wright, 1953, pp.516521). In 1970, in the "Reports on Progress in Physics" J Anketell and R W Nicholls demonstrated that to understand the glow effect

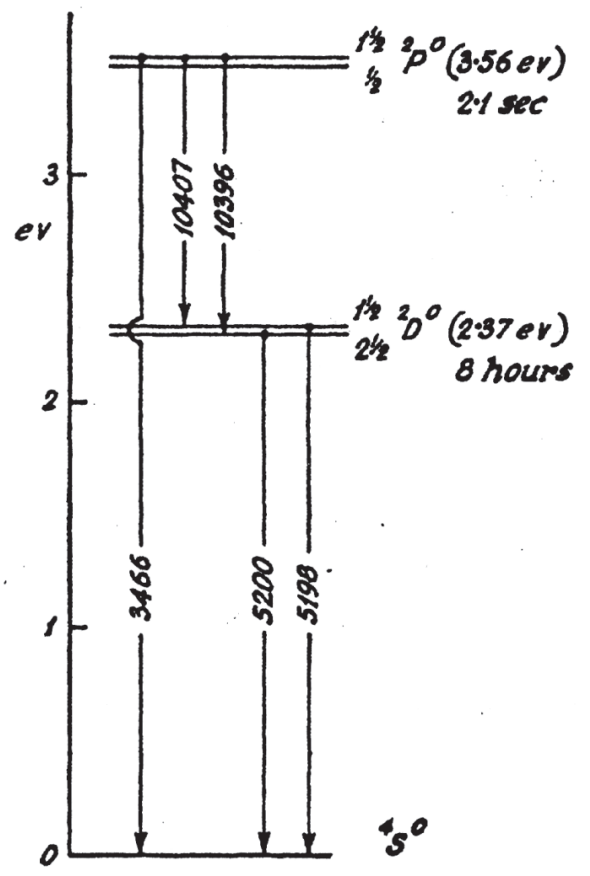

Fig. 6. A Nitrogen atom and its energy levels in metastable states. The active nitrogen, that is, atoms in the ground and metastable state are produced by dissociative recombination of $\mathrm{N}_{2}^{+}$ions and electrons (Courtesy "Physical Review") (Mitra, 1953, pp.516-521).

and its spectroscopic interpretation, the understanding of other processes, such as collision-induced vibrational relaxation, is needed (Anketell and Nicholls, 1970, pp. 269-306).

Mitra's work was an integrated part of the scientific community within India and abroad. Not surprisingly, he was invited to send proposals for the Nobel Prizes ${ }^{10}$, and was nominated for the Fellowship of the Royal Society of London (details below).

\section{S K Mitra's Nomination fOR the Fellowship of the Royal Society London}

The study of old nomination certificates shows that at least six Fellows should sign the certificate "From Personal Knowledge" and "From General Knowledge." For example, M N

\footnotetext{
${ }^{10}$ For more details on M N Saha's nomination by S K Mitra, see, Singh R., Nobel Prize nominator Sisir Kumar Mitra F R S - His scientific work in international context, Shaker Verlag, Aachen, 2014, pp. 107-132.
} 


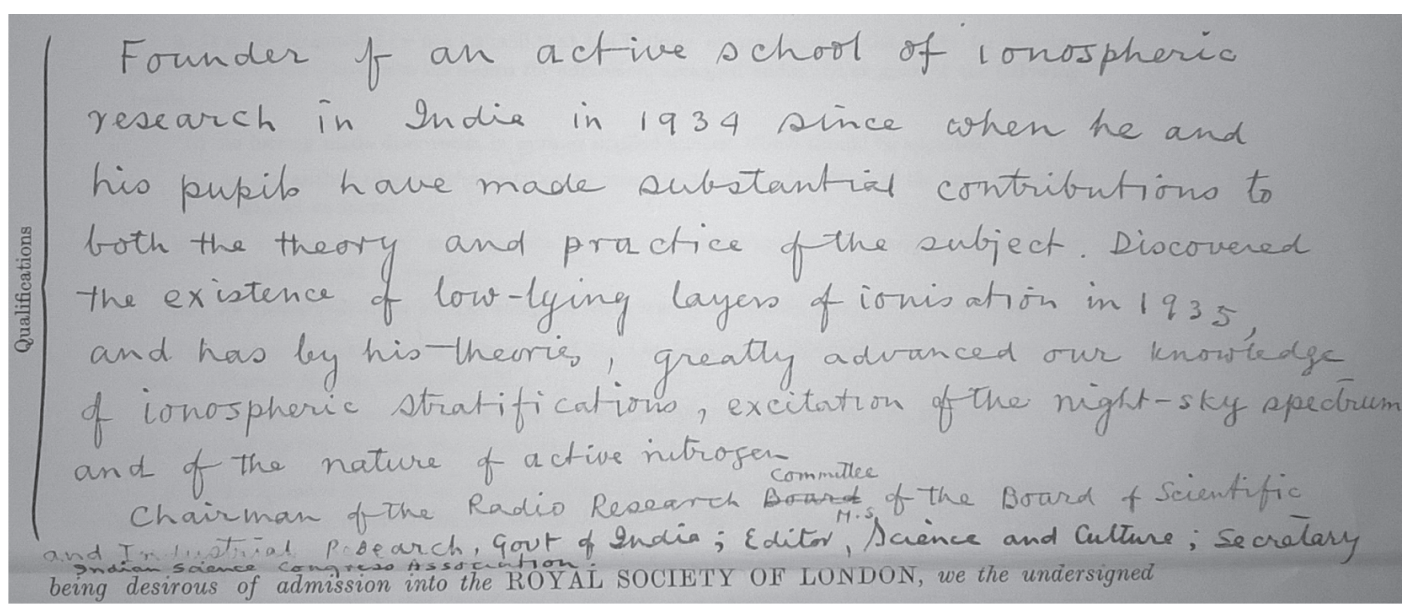

Fig. 7. A part of S.K. Mitra's nomination certificate for the Fellowship of the Royal Society (Credit: Archive Royal Society London)

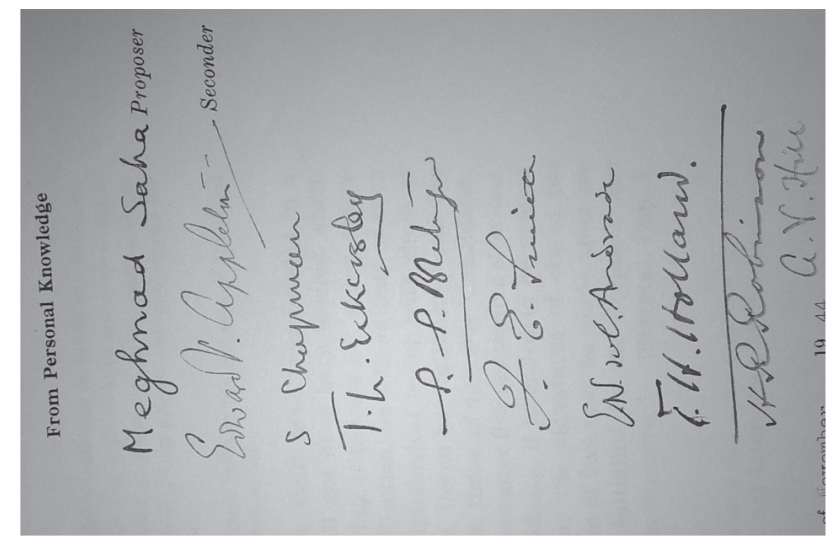

Fig. 8. S K Mitra's Nominators for the F R S (Credit: Archive Royal Society London)

Saha's certificate was signed by three FRS "From Personal Knowledge"; and by four "From General Knowledge." The person standing on the first place is called "Proposer" and his immediate supporter as "Seconder." The nomination certificate is valid for five years. On Nov. 27, 1944, Mitra was nominated for the Fellowship of the Royal Society for his various contributions (Fig. 7).

His "Proposer" and "Seconder" were M N Saha and E V Appelton respectively. Eight more scientists signed the certificate from personal knowledge (Fig. 8).
Mitra's certificate was "suspended" (which means that the certificate was displayed in the building of the Royal Society London) in 1945, 1946, 1947, 1948 and 1949. According to the rule, after five year it expired.

According to the rules and regulations of the Royal Society, in addition to being considered for Fellowship in the "Mainstream group" (that is, for contribution to scientific knowledge), Mitra could also be considered for either under the group "Applied Science candidate" or "General Candidate." The first case would cover things like the making of a new device; whereas the second case covered leadership or inspiration or help in the public understanding of science (Mitra, 1938, pp.914-915).

The next time Mitra was proposed "From Personal Knowledge" by M N Saha, H S W Massey, E V Appleton, H S Jones, J B S Haldane, A V Hill and S Chapman. The wording of the nomination certificate shows that Mitra's supporters seemed to indicate that his case can also be considered under "General candidates":

\footnotetext{
"Distinguished for his researches on the Ionosphere, on airglow and on the nature of active nitrogen. Founder and leader of an active school of Ionospheric research in India. Was instrumental in establishing
} 
the Radio Research Committee (of the Council of Scientific and Industrial Research, Government of India), of which he was the first Chairman. General President, Indian Science Congress Association (1954-1955). His comprehensive treatise on the Upper Atmosphere has received world-wide recognition and is the first book of its kind. It is in many respects an original contribution and has stimulated researches on the high regions of the atmosphere. Author of a large number of papers by himself and his pupils, of whom he was the inspirer."

In 1958, Mitra was elected as Fellows of the Royal Society of London. With that he got the right of nomination. How many Indian scientists were proposed by him remains a mystery; because, according to rules and regulations of the Royal Society, documents older than 50 years can be consulted for research work.

\section{Conclusions}

Seen in the context of the Nobel Prizes and Fellowship of the Royal Society of London, S K Mitra was the most successful physicists from "Raman's physics school" in Calcutta. He was India's only physicist who got more than 3 invitations to propose candidates for the Nobel Prize. He was nominated for the Fellowship of the Royal Society by his Indian and British peers. This shows the recognition of his scientific work by the international scientific community. Surprisingly, he is not well-known as C V Raman, M N Saha, S N Bose and H J Bhabha. Why so? This needs further research.

S K Mitra started research on optics and later changed to radio technology and consequently to ionosphere science. This came due to his stay in France; where he got the opportunity to specialize in radio technology. Mitra's life history shows that staying abroad by a scientist can give impulses to start a new field of research in his own country.

In spite of poor support from the Government, Mitra and his associates "experimentally discovered the D-layer", gave plausible "explanation of the origin of E-layer", and observed different aspects of D-, E- and Flayers. Evidently, a good researcher needs not much money to make inventions.

\section{ACKNowledgements}

I am thankful to the Editor of Indian Journal of History of Science for editorial work. Thanks are due to Ms. Joanna Hopkins, Archive Royal Society of London, for S K Mitra's documents. J C Bose's letter to the V C, University of Calcutta was given to me by "anonymous". I acknowledge his help. I am grateful to Prof. Dr. Michael Komorek, Head of the Research Group Physics Didactics and History of Science, for supporting my research work by providing research facilities.

\section{BiBLIOGRAPHY}

Anketell, J and Nicholls R W. The afterglow and energy transfer mechanisms of active nitrogen, Rep. Prog. Phys. 33(1970):269-306

Anonymous. Societies and academies, Nature 27(1883): 403-405.

Anonymous. Societies and Academies, Nature 111(1923): 727.

Appleton, E V and Barnett M A F. On some direct evidence for downward atmospheric reflection of electric rays, Proc. R. Soc. Lond. 109(1925):621-641.

Appelton, E V. Two anomalies in the ionosphere, Nature 157(1946):691-691.

Banerjee, P; Ray, N; Guha, B et al., Hundred years of the University of Calcutta, University of Calcutta, Calcutta, 1957.

Benson, J M. Measurements of the properties of active nitrogen, J. Appl. Phys. 23(1952):757-764.

\footnotetext{
${ }^{11}$ R.S.L., http://royalsociety.org/DServe/dserve.exe?dsqIni=Dserve.ini\& dsqApp=Archive\&dsqDb=Catalog\&dsqSearch= $\mathrm{RefNo}==\% 27 \mathrm{EC} \% 2 \mathrm{~F} 1958 \% 2 \mathrm{~F} 19 \% 27 \&$ dsqCmd=Show.tcl, Nov. 3, 2013.
} 
Bose, D M. Ions and electrons in action, Sci. Cult. 76(2010):510-517.

Chattopadhyay, A. Biographical dictionary of Indian scientists from ancient to contemporary, Rupa Co., New Delhi, 2002, pp. 827-828.

Das Gupta, M K. Reflections - Professor Sisir Kumar Mitra - As I remember him, Resonance 5(2000):92-99.

Fleming, J A. The thermionic valve and its developments in radiotelegraphy and telephony, The Wireless Press Ltd., London, 1919, p. 1.

Gaydon, A G. Active nitrogen - A new theory by Prof. S.K. Mitra, Nature 157(1946):751.

Ghosh, S N and Ghosh A. Professor S.K. Mitra - His pioneering work on radio science, Curr. Sci. 68(1995):1150-1159.

Gutton, G; Mitra; S K; Ylöstalö, V. Sur la décharge á haule fréquence dans les gaz rarefies, C.R. Acad. Sci. (Paris) 176(1923):1871-1874.

Herman, L and Herman R. Mechanism of the emission spectrum of active nitrogen, Nature 161(1948):10181019.

Hertz, H. Versuche über die Glimmentladung, Ann. Phys. 225(1883):782-816.

Kocchar, R. Indian Fellows of the Royal Society, London (1841-2000), Curr. Sci. 80(2001):721-722.

Lewis, P. Some new fluorescence and afterglow phenomena in vacuum tubes containing nitrogen, Astrophysical J. 12(1900):8-15.

Mahanti, S and Sisir Kumar Mitra - A pioneer in radio physics, Dream 2047 (2003):29-34.

Mitra, A P. Sisir Kumar Mitra, Resonance 5(2000):3-4

Mitra, S K. On a new geometrical theory of the diffractionfigures observed in the heliometer, Proc. Indian Assoc. Cult. Sci. 6(1920):1-18.

Mitra, S K. On the diffraction of light by apertures having the form of a segment of a circle, in: Sir Asutosh Mookerjee Silver jubilee, Vol. II, Science, University of Calcutta, Calcutta, 1922, pp. 229-235.

Mitra, S K. Sur la desaimantation des fer par des oscillations electriques, C.R. Acad. Sci. (Paris) 176(1923):12141217.

Mitra, S K. Determination of spectroscopic standard wavelengths in the short wave-length region, Ann. Physique 19(1923):315-339.
Mitra, S K and Rakshit, H. Refraction of light waves by electrons, Nature 123(1929):796-797.

Mitra, S K and Sil, B C. On the variation of the resistance of thermionic valves at high frequencies, Phil. Mag. 13(1932):1081-1098.

Mitra, S K; Rakshit, H and Syam P., et al., Effect of solar eclipse on ionosphere, Nature 132(1933):442-443.

Mitra, S K and Syam, P. Absorbing layer of the ionosphere at low height, Nature 135(1935):953-954.

Mitra, S K. Atmospherics, Sci. Cult. 2(1936):430-432.

Mitra, S K. Ionospheric studies in India, Nature 137(1936):503-504.

Mitra, S K. Need of a Radio Research Board for India, Sci. Cult. 14(1936):755-758.

Mitra, S K. The ozonosphere and the early morning increase of the E-layer ionization of the ionosphere, Sci. Cult. 3(1938):496-497.

Mitra, S K. Origin of the E-layer of the ionosphere, Nature 142(1938):914-915.

Mitra, S K; Bhar, J N and Ghosh, S P. The lower ionosphere, Ind. J. Phys. 12(1938):455-465.

Mitra, S K. Need for a planned development of broadcasting in India, Sci. Cult. 6(1940):249-250.

Mitra, S K. Light of the night sky, Sci. Cult. 9(1943): 4648.

Mitra, S K. Nature of active nitrogen, Sci. Cult. 9(1943): 49-50.

Mitra, S K. Active nitrogen and $\mathrm{N}_{2}^{+}\left(\mathrm{x}^{\prime}\right)$ ions, Nature 154(1944): 212-213.

Mitra, S K. Energy imparted by active nitrogen, Nature 155(1944): 831.

Mitra, S K. Variations in the after-glow brightness of active nitrogen under varied experimental conditions, Nature 154(1944): 576-577.

Mitra, S K. Ionisation in active nitrogen, Sci. Cult. 10(1944):133-134.

Mitra, S K. Active nitrogen - A new theory, Indian Press Ltd., Calcutta (1945): 61.

Mitra, S K. Active nitrogen, Phys. Rev. 90(1953): 516-521.

Mitra, S K and Kundu, M R. Thunderstorm and sporadic E ionisation of the ionosphere, Nature 174(1954): 798799. 
Morrem A. Resultate einer Untersuchung über die Phosphoreszenz verdünnter Gase, Ann. Phys. 191(1862): 350-352.

Morrem, A. Ueber die mit dem Namen Phosphorenz belegten Licht-Erscheinungen in sehr verdünnten Gasen bei und nach dem Durchgang elektrischer Funken, Ann. Phys. 202(1865): 643-654.

Rakshit, H. On the distribution of space charge between a plane hot cathode and a parallel anode, Phil. Mag. 7(1930):80-87.

Rakshit, H. On an estimation of the height of the Heaviside layer in Bengal, Phil. Mag. 7(1931): 897-907.

Rakshit, H. Radio field-strength survey of the city of Calcutta and its suburbs, Phil. Mag. 7(1931):174-184.

Ramanathan, K R. Sisir Kumar Mitra memorial lecture, Proc. Nat. Inst. Sci. (India) 35(1967): 268-281.

Ratcliffe, J A. Sisir Kumar Mitra (1890-1963), Bio. Mem. Fell. R. Soc. Lond. 10 (1964):221-228

Saha, M N. Progress of physics in India during the past twenty five years, in: Prashad B. (Ed.), The progress of science in India during the past twenty five years, Indian Science Congress Association, Calcutta (1938): 674-741.

Sarasin, E. Von der Phosphoreszenz verdünnter Gase nach dem Durchgang einer elektrischen Entladung, Ann. Phys. 216 (1870):425-434.

Singh, R. Nobel Prize nominator Sisir Kumar Mitra F.R.S. - His scientific work in international context, Shaker Verlag, Aachen, 2014.

Singh, R. Chemistry and Physics Nobel Prizes - India's Contribution, Shaker Publisher, Aachen, (2016): 164.

Singh, R. B.B. Ray under the influence of C.V. Raman and M.N. Saha, Sci. Cult. 83(2017):84-91.

Strutt, R J. Bakerian lecture - A chemically active modification of nitrogen produced by the electric discharge, Proc. R. Soc. Lond. 85(1911):219-229.

Trowbridge, C C. Spectra of meteor trains, Proc. Nat. Acad. Sci. (U.S.A.) 10(1924):24-41;

Wright, A N. Active nitrogen, Academic Press Inc., New York, 1968. 